\title{
Work-life balance: Is it still a new concept in private commercial banking sector of Bangladesh?
}

Newaz, Mohammad Tanvi $₫$

BRAC University, Bangladesh (tanvi@bracu.ac.bd)

Zaman, Kanij Fatama

Northern University Bangladesh, Bangladesh (Kfmridula@gmail.com)

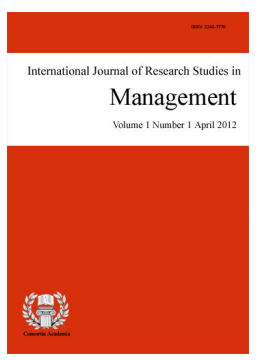

ISSN: $2243-7770$ Online ISSN: 2243-7789

Received: 18 April 2012

Available Online: 22 June 2012

\section{Abstract}

This paper represents the current scenario of work-life balance in private commercial banks of Bangladesh which indicates a pessimistic approach has been adopted by the management. Apart from the multinational banks, most of the national banks are not aware of this concept and hardly have any policy regarding the work-life balance issues. At this moment, different socio-economic barriers and lack of human right awareness may support the management for not taking this issue seriously. However, if they want to achieve their business objectives through the development of the human resource then there is no alternative to develop the working lives of their workforce. This paper recommends management should consider the nature of business and background of employees they have employed and customize their policies with the participation of the employees. This paper also discusses some other recommendations considering the perspectives of both parties as well as the perspectives of Bangladesh.

Keywords: work-life balance; work-life conflict; private commercial bank; Bangladeshi banking sector; flexible working schedule 


\section{Work-life balance: Is it still a new concept in private commercial banking sector of Bangladesh?}

\section{Introduction}

In the new millennium, contemporary organizations are benefited from a global, diverse, technologically savvy and highly productive workforce but it is ironic that these workforces also find it difficult to have a good balance between their work life and family life (Siegel, Brockner, Fishman, Post, \& Garden, 2005). Work-life balance can be seen as the extent to which an individual is equally engaged in-and equally satisfied with his or her work role and family role (Greenhaus, Collins, \& Shaw, 2003). Businesses are facing increasing demands to raise efficiency and becoming more responsive to customers and employees. No longer is it just a matter of remuneration and promotional prospects; job seekers are increasingly making employment decisions on how well their current or potential workplace can support a balance between personal lives and paid occupation. On the other hand, organizations, failing to make their work environments flexible, are beginning to see a brain drain and loosing highly skilled professionals to more flexible organizations (Dunne, 2007). The objectives of this research paper are to identify the status of work-life balance in private banking sector of Bangladesh as well as to provide some recommendations considering the scenario of a developing country like Bangladesh.

\section{Literature review}

Aryee, Srinivas, and Tan (2005) and Lewis and Cooper (1999) state, changing economic trends, demographic shifts, technological advances and competitive forces have made the work-life balance a pertinent area of concern to scholars, individuals and organizations across the globe (as cited in Baral \& Bhargava, 2011, p. 220). A lot of researches have been done to identify an acceptable definition of 'work-life balance'; still there is a very little evidence to get an ideal definition so far. Most of the major reviews of work-family relations either do not mention work-family balance or mention balance but do not explicitly define the concept (Greenhaus, Collins, \& Shaw, 2003). Moreover, empirical studies that discuss balance between work and family roles generally do not distinguish from other concepts in the work (Greenhaus, Collins, \& Shaw, 2003). As Burke (2004) and Lewis at el (2007) argue, 'wok-life balance' is a contested term because the term 'balance' suggest that work is not integral to life and it implies a simple tradeoff between the two spheres as it encourages quick-fix solutions that do not address fundamental inequalities, and that therefore shift responsibility for balancing work and home life onto individuals (as cited in Gregory \& Milner, 2009, p. 2).

The main message of this debate is the need for 'good work-life balance', on the other hand, the debate and successive policy are frequently based on theories about work and life copied from dull readings of empirical data or misconceptions about employee attitudes to work and life. According to IDS (2000), the work-life balance debate presumes that individuals have too much work rather than too little work - a debilitating working hour culture is said to be persistent (as cited in Eikhof, Warhurst, \& Haunschild, 2007, p. 326). In addition, it is also claimed in some cases, work is not just ruling but also ruining our lives (Eikhof, Warhurst, \& Haunschild, 2007). According to Fafnani and Letablier (2004), in France campaigns for reducing working time have rallied around the phrase 'work less, live better' (as cited in Eikhof, Warhurst, \& Haunschild, 2007, p. 326).

However, according to Eikhof, Warhurst, and Haunschild (2007), having to service a 24/7 econmy, emplyers need to move away from 9 to 5 work day. Flexible working hours are offered as work-life balance allowing employers to appear employee-friendly whilst meeting business needs. Although the HR sector is increasingly seeing wok life balance as a means of motivating staff and improving recruitment and retention, formal strategies are still lacking in 48 percent of UK organizations, with alomost twice as many of their counterparts in Europe offering flexible working arrangements to staff (Dunne, 2007). According to Schneider, Ganopolski, and Rahmstorf (2006), 83 percent of employers in German Rheinland-Pfalz offered flexible hours (as cited in Eikhof, 
Warhurst, \& Haunschild, 2007, p. 328). Nevertheless, Bell, and Bryson (2005) argue, are employers really making flexible work opportunities availbale equally to both sexes? Do both sexes want such opportunities? The evidence suggests, it is mainly women - particularly mothers - who want flexible working arrangements as they struggle to cope with the 'triple burden' of work, home and childcare (Bell \& Bryson, 2005). On the other hand, Boles and Hollenberg (1997) argue, work family argument is not limited to only married individuals with or without children, single parents and other single individuals may have difficulty in balancing work with children, friends relatives and other commitments outside the orgainzations (as cited in Karatepe \& Tekinkus, 2006, p. 175).

The study of Baral and Bhargava (2011) indicates that from an organizational perspective, involvement in family roles should not be viewed as an obstruction, since it provides opportunities to acquire skills, knowledge and increase efficiency to perform better at work and vice versa. As a result, organizations should make efforts to stimulate the experience of enrichment. Greenhaus, Collins, and Shaw (2003) argue, the beneficial effects of balance are based on the assumption of positive balance and positive balance has a more substantial positive impact on quality of life than negative balance. They suggest that an equally high investment of time and high association in work and family would diminish work-family conflict and stress thereby enhancing an individual's quality of life. On the other hand, Hobson, Delunas, and Kesic (2001) accumulated a number of long research findings based on U.S. employees and tried to assess the outcomes of not having a proper work-life balance in organizations. The findings include - increased levels of stress and stress-related illness, higher rates of family strife, violence and divorce, higher rates of absenteeism and turnover, reduced productivity and job satisfaction. However, the existence of work-life balance in itself does not create difficulties and offence within organizations; rather, in situations where there is already excessive workloads, under-staffing, and last minute, unpredicted tasks, the existence of work-life balance is likely to exacerbate the situations (Drew \& Murtagh, 2005).

Nonetheless, there are quite a few research studies on work-family conflict in developing countries like India and Bangladesh and one of the reasons could be the lack of awareness of this issue as well as the lack of awareness of equal employment opportunity act. According to Baral and Bhargava (2011), a study on work-family enrichment in India would be prudent because of its cultural roots, where people consider work as a source of earning and social status. At the same time, for people in India, family is a social institution that provides not only emotional support but also stands with them in times of crisis (Baral \& Bhargava, 2011). The same scenario is very much pertinent in Bangladesh.

\section{Research Hypotheses}

The purpose of the study was to find out the present scenario of the work-life balance policy in private banking sector of Bangladesh. Here the researchers also want to divide the employees of the private banks in Bangladesh into different groups to help the banks to customize their work-life balance policy according to the needs of these groups.

Related to the objective, the constructed four hypotheses are as follows:

$\mathrm{H}_{1}$ (a): More than $50 \%$ employees say that their organizations have no separate work-life balance policy.

(b): More than $30 \%$ employees say that their organizations have a separate work-life balance policy.

$\mathrm{H}_{2} \quad$ More than $80 \%$ employees agree that their organizations should customize the work-life balance policy to meet individual needs.

$\mathrm{H}_{3} \quad$ More than $80 \%$ employees say that good work life balance policy make employee committed.

$\mathrm{H}_{4} \quad$ (a): Less than $20 \%$ employees say that too much work load is the main reason for their extra work time. 
(b): More than $50 \%$ employees say that meeting / training is the main reason for their extra work time.

\section{Research Methodology}

\subsection{Sources of data}

Both primary and secondary data have been used for the purpose of the study. Primary data have been collected through a questionnaire. The questionnaire consists of 20 items: seven items on demographic characteristics of the respondents and remaining thirteen items are related to issues on work-life balance of the respondents. Issues such as working hour, time spent with children, spouse working status, organization's work-life balance programs, work load, perception of the employees about the work-life balance programs of their organizations, willingness to stay in the organization and many other factors have been examined here. Secondary data have been collected from different books, publications, research studies, journals, articles, and websites.

\subsection{Sample Size and Department}

The sample of the study covers the employees from banking sector of Bangladesh. A sample of 220 employees (149 male and 71 female) has been selected purposively from different departments (Table 1) from 10 Banks. Data have been collected by non probability sampling and conveniently.

\section{Table 1}

Samples in terms of Bank and Gender

\begin{tabular}{lrrr}
\multicolumn{1}{c}{ Bank Name } & \multicolumn{2}{c}{ Gender } & \\
& Male & Female & Total number of samples \\
\hline One Bank Limited & 17 & 5 & 22 \\
Citibank N.A. & 4 & 8 & 12 \\
Standard \& Chartered Bank & 15 & 5 & 20 \\
Prime Bank Limited & 16 & 11 & 27 \\
Arab Bangladesh Bank Limited & 20 & 5 & 25 \\
Commercial Bank of Ceylon & 15 & 7 & 22 \\
Mutual Trust Bank Limited & 12 & 6 & 18 \\
Dutch Bangla Bank Limited & 13 & 11 & 24 \\
Islami Bank Bangladesh Limited & 22 & 3 & 25 \\
Eastern Bank Limited & 15 & 10 & 25 \\
Total & 149 & 71 & 220 \\
Percentage & $67.7 \%$ & $32.3 \%$ & $100 \%$ \\
\hline
\end{tabular}

\subsection{Measures}

After collecting the data, data have been entered in SPSS (Statistical Package for the Social Sciences) version 17. The data have been analyzed by Cluster analysis deals with data objects similarity. It solves the set of objects splitting into several previously non-specified groups (clusters) so that the objects in the single clusters are the most similar to each other as possible and the objects outside of the different clusters should bear the most dissimilarity (Everitt, Landau, \& Leese, 2001). Cluster analysis can be realized by many different methods. Here, the researchers have been used two-step cluster analysis. Two-Step can create cluster models based on both continuous and categorical variables. Moreover, the method can automatically determine the optimal number of clusters. So, the most suitable method for data proceeding in this survey seems to be the two-step method. 


\subsection{Input}

The data that have been used for the study have been obtained from banking sector of Bangladesh. The data contains data of 220 cases and are presented in a table in SPSS. This table contains information about the gender, management level, experience, type of employment, marital status, working hour, time spent with children, time spend travelling to work, does organizations have a separate policy for work-life balance, types of work-life balance policy, stress-related disease suffered by the employees, need for customized work life balance policy, work load, reasons for extra work time, and many others.

The database contains all categorical variables. Because the researchers have only categorical data, they have only log-likelihood option for distance measure. In the first running, here researchers have chosen BIC to determine the number of clusters. The researchers have presented those obtained with BIC indicator in appendices (TableA1).

\subsection{Output}

In the first running, the researchers have chosen BIC to determine the number of clusters. In appendices (Table A1), the highest ratio of distance measures' is for three (3) clusters, according to the SPSS algorithm; the optimal number of clusters is also three (3). The cluster distribution is shown in Table 2 and the cluster pie chart (Figure A1) shows the relative size for three clusters solution.

Table 2

Cluster distribution

\begin{tabular}{lcccc}
\hline & & $\mathrm{N}$ & \% of Combined & \% of Total \\
\hline Cluster & 1 & 70 & $32.0 \%$ & $31.8 \%$ \\
& 2 & 56 & $25.6 \%$ & $25.5 \%$ \\
& 3 & 93 & $42.5 \%$ & $42.3 \%$ \\
& Combined & 219 & $100.0 \%$ & $99.5 \%$ \\
Excluded Cases & 1 & & $.5 \%$ \\
\multicolumn{2}{l}{ Total } & 220 & & $100.0 \%$ \\
\hline
\end{tabular}

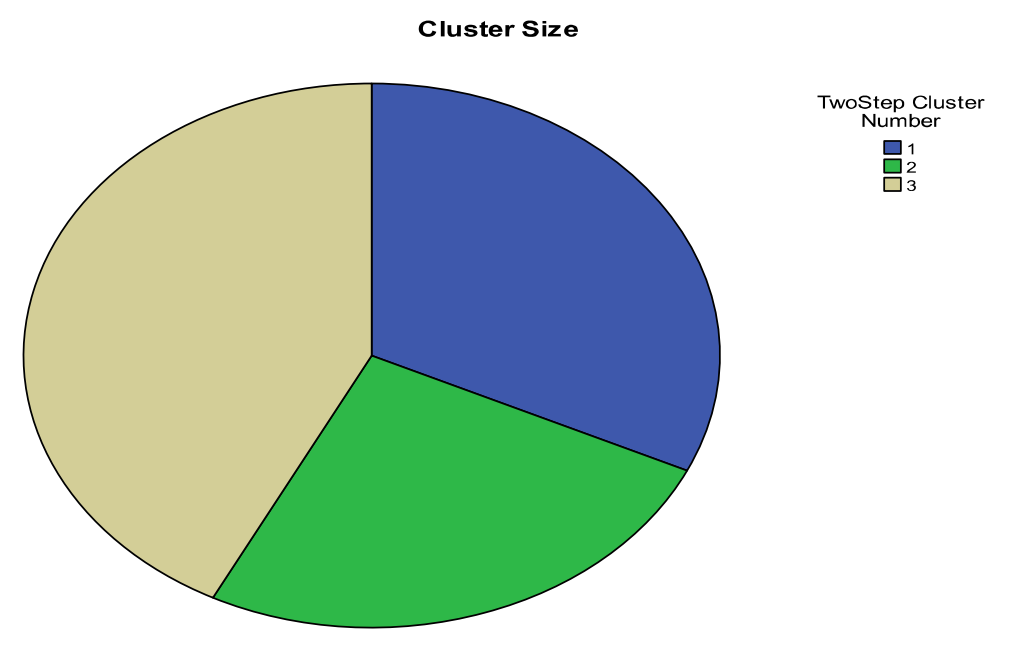

Figure 1. Cluster size

SPSS gives the importance plot for each variable (categorical). In appendices (Figure A1, the researchers have presented the importance of the categorical variables for the three clusters. Note that Parents, Marital status, Work experience, Management level contribute the most to differentiate the first cluster (Appendices: Figure A1) 
Newaz, M. T. \& Zaman, K. F.

and Parents, Marital status, Separate Work-life Balance policy, Intension to Switch differentiate the second cluster (Appendices: Figure A1). Time spent with children, marital statuses, Separate Work-life Balance policy, Type of employment differentiate the third cluster (Appendices: Figure A1).

\section{Discussion}

On the basis of variables no. 1 to 20 the cluster analysis has been performed, namely the procedure from SPSS Two Step Analysis, which has created three (3) clusters. Resulting clusters of Two Step Analysis are described as follows:

\section{Cluster No. 1 (71 respondents)}

The first cluster, which fills 71 respondents (32.0\%), contains mostly single male (69\%), full time (29.4\%) employees of 25-34 years old (39.1\%) and working experience is no longer than 2 years because most of them occupy entry level management positions $(49.1 \%)$.

\section{Cluster No. 2 (56 respondents)}

The second cluster, which fills 56 respondents (25.5\%), contains married male (20.1\%) and female $(37.1 \%)$ full time (52.0\%) and contractual (48.0\%) employees of 25-34 years old (34.4\%), working experience is no longer than 3 years because most of them occupy entry and mid level management positions, average working hour is $8-9$ hours per day.

\section{Cluster No. 3 (93 respondents)}

The third cluster, which fills highest respondents $(42.5 \%)$, contains mostly married $(63.4 \%)$ male $(43.6 \%)$ full time (48.0\%), employees of 25-45+ years old and most of them have children (94.3\%) and working experience is longer than 5 years because they occupy mid level and top level management positions, average working hour is 9-10 hours per day. The most important thing for this group is that they avail transportation and health program as additional facility provided by their organizations.

\subsection{Hypotheses Testing}

To test the hypothesis one-tailed Z-test and two-tailed Z-test has been used. The results of the Z-test are presented below.

$\mathbf{H}_{1}$ : While testing the hypothesis, the $\mathrm{z}$-calculated value 0 is greater than the z-table value -1.6 at significance level 0.05 . So we cannot reject the $\mathrm{H} 1$ (a) that means more than $50 \%$ employees say their organization have no separate work-life balance policy. As testing the hypothesis, the z-calculated value 1.29 is greater than the z-table value -1.65 at significance level 0.05 . So we can not reject the H1 (b). That means more than $30 \%$ employee say that their organizations have separate work-life balance policy.

$\mathbf{H}_{2}$ : While testing the hypotheses, the z-calculated value 2.6 is greater than the $\mathrm{z}$ - table value -1.65 at significance level 0.05 . So we cannot reject null hypothesis. So employees who agree that the organization should customize the work-life balance policy to meet individual needs are more than $80 \%$.

$\mathbf{H}_{3}$ : While testing the hypothesis, the $\mathrm{z}$ - calculated value -6.3 is less than the $\mathrm{z}$ - table value -1.65 at significance level 0.05 . So we cannot accept the null hypothesis. So employees who say good work life balance policy make employee committed is not more than $80 \%$.

$\mathbf{H}_{4}$ : As testing the hypothesis, the $\mathrm{z}$ - calculated value -2.22 is less than the $\mathrm{z}$-table value 1.96 at significance level 0.05 . So we cannot reject the $\mathrm{H} 4$ (a). So, less than $20 \%$ employees say that too much work loads are the main reasons for their extra work time. While testing the hypothesis, the $\mathrm{z}$ - calculated value -4.12 is less than the $\mathrm{z}$ - table value -1.65 at significance level 0.05 . So we cannot accept the $\mathrm{H} 4$ (b) that means the employees who say 
Work-life balance: Is it still a new concept in private commercial banking sector of Bangladesh?

that meeting / training is the main reason for their extra work load is not more than $50 \%$.

\section{Findings and Analysis}

The findings from the study indicate that the employees of the banking sector in Bangladesh can be divided into three groups. Namely cluster1, cluster2 and cluster3. The main difference between these three clusters is shown below (Table 3).

Table 3

Cluster Information

\begin{tabular}{|l|}
\hline \multicolumn{1}{|c|}{ Cluster 1 } \\
\hline $\begin{array}{l}\text { Unmarried 18-34 years old full time male employees occupying mainly entry level management position. They } \\
\text { avail counseling services as additional facility provided by their organizations. }\end{array}$ \\
\hline \multicolumn{1}{c|}{ Cluster 2 } \\
\hline $\begin{array}{l}\text { Married 25-34 years old full time and contractual male and female employees occupying mainly entry level } \\
\text { management position. They avail health programs as additional facility provided by their organizations. }\end{array}$ \\
\hline \multicolumn{1}{c|}{ Cluster 3 } \\
\hline $\begin{array}{l}\text { Married 25- 45+ years old full time mostly male and some female employees occupying mid and top level } \\
\text { management positions. They avail transports and health programs as additional facilities provided by their } \\
\text { organizations. }\end{array}$ \\
\hline
\end{tabular}

Researchers' hypotheses testing parts relating to whether organizations have separate work-life balance policy shows $50 \%$ employees say that their organizations have no separate work-life balance policy and $30 \%$ employees say their organizations have a separate work-life balance policy. Hypotheses testing parts also shows that more than $80 \%$ employee agree that the organization should customize their work-life balance policy to meet individual needs and the employees who say that good work life balance policy make employee committed is not equal to $80 \%$. Hypotheses testing parts also show that more than or equal to $20 \%$ employees say too much work load and more than 50\% employees say meeting / training are the main reasons for over time.

\section{Recommendations and practical implications}

The findings of the study have practical implications for organizations and individuals. Majority of the employees in private banking sector are not familiar of this concept since their organizations $(50 \%$ of the reviewed banks) don't have any work-life balance policy. At the present era of globalization, when multi-nationals are developing their management practices with excellence, it should be a pro-active step for the Bangladeshi private banks to adapt the policy. Work-life balance policy not only enhances the harmonious employment relationship, it also helps organizations to improve the productivity of the employees. In a developing country where nearly $40 \%$ of the people are underemployed (Indexmundi, 2010) may assist the management to make people work more but the situation will change soon because of the dissemination of ethical knowledge and operation of the multinationals in developing countries. However, government should take initiatives to make it as one of employment rules by introducing the work-life balance policy which will eventually foster the improvement of the livelihood of people.

$80 \%$ of the respondents support the concept of customization of work-life balance policy for individual need but organizations should be careful while customizing this policy. It is highly questionable, what would be the basis of customization, such as: gender, age, level of hierarchy or nature of task done by individual? A thorough analysis of the demographic background of the employees should be done before customizing this policy. Beside that participation of all level of employees in policy formulation can eliminate this problem as well as proper communications can also ensure the successful implementation of this policy. On the other hand, the line managers are the crucial thespian to implement this policy and apparently, it will be the responsibility of top management to educate them. In addition, continuous training programs should be arranged frequently for all level of employees to solve any issue regarding work-life balance. 
Most of the respondents $(80 \%)$ do agree that work-life balance can make them more committed which will work as an intrinsic motivation. Moreover, it also helps to build a positive psychological contract and better job satisfaction for the employees which will ultimately assist to increase the retention rate. In apparent recognition of this finding, managers should establish trust in employees, build high standard of excellence, and where necessary, delegate authority in order to enhance employees' intrinsic motivation.

Management should arrange regular training on time management to dvelop the productivity of the employees as well as to improve the work-life balance scenario in the organization. However, all the training should be conducted within the office hour so that outcomes of these training programs remain encouraging and provide a sense of positiveness for work-life balance concept. The findings of the study indicates that the positive interaction between work and family is a new paradigm to explain the relationship between individual and organization. Managemetnt should take this opportunity to attract and retain talents in order to gain competitive advantage over their competitiors. In addition, adapting a strategic approach will help them to develop their employees through organizational involvement as well as give them back the investment they make on their human resource.

\subsection{Limitations and future research}

Present study should be considered in light of certain limitations. The number of reviewed banks was 10 compared to 31 private banks operating in Bangladesh. A larger sample size would give a better outcome indeed. Apparently, most of the respondents were male as the participation of female in workplaces of Bangladesh is still low. On the other hand, it would be difficult to make broad generalizations from our result to other industry and it may not be transferable outside Bangladeshi context. Future research should be conducted considering the above scenario. The impact of unemployment rate, economical condition, participation of female in workplaces and marital status in work-life balance practices may possibly be explored in future research.

\section{Conclusion}

For a developing country like Bangladesh, it might be difficult to implement work-life balance practices since considering people as a resource and spending money to develop them and introducing practices to ensure a better work life are yet to be familiar ideas for most of the organizations. However, the perception of work-life balance is not a conflicting one between profit and loss. Rather, it is just like another contemporary idea to make organizations more productive and get benefited from a win-win situation in the workplaces. Nevertheless, if the bottom line is that employees bring the competitive advantages for the organizations then undoubtedly organizations need to be competitive while managing their employees.

\section{References:}

Baral, R., \& Bhargava, S. (2011). Predictors of work-family enrichment: moderating effect of core self-evaluations. Journal of Indian Business Research , 3(4), 220-243. $<$ http://dx.doi.org/10.1108/17554191111180573>

Bell, A., \& Bryson, C. (2005). Work-life balance - still a 'women's issue'? British Social Attitudes: The 22nd Report.

Drew, E., \& Murtagh, E. M. (2005). Work-life balance: senior management champions or laggards? Women in Management Review, 20(4), 262-278. <http://dx.doi.org/10.1108/09649420510599089>

Dunne, H. (2007). Putting balance into business: Work life balance as a buiness strategy for avoiding brain drain. Strategic HR Review, 6(6), 28-31. <http://dx.doi.org/10.1108/14754390780001014>

Eikhof, D. R., Warhurst, C., \& Haunschild, A. (2007). Introduction: What work? What life? What balance?

Critical reflection on the work-life balance debate. Employee Relations , 29(4), 325-333. $<$ http://dx.doi.org/10.1108/01425450710839452>

Everitt, B. S., Landau, S., \& Leese, M. (2001). Cluster analysis (4 ${ }^{\text {th }}$ ed.). London: Arnold. 
Work-life balance: Is it still a new concept in private commercial banking sector of Bangladesh?

Greenhaus, J. H., Collins, K. M., \& Shaw, J. D. (2003). The relation between work-family balance and quality of life. Journal of Vocational Behavior, 63(February), 510-531. $<$ http://dx.doi.org/10.1016/S0001-8791(02)00042-8>

Gregory, A., \& Milner, S. (2009). Editorial: Work-life balance: A matter of choice. Gender, Work and Organization, 16(1), 1-13. <http://dx.doi.org/10.1111/j.1468-0432.2008.00429.x>

Hobson, C. J., Delunas, L., \& Kesic, D. (2001). Compelling evidence of the need for corporate work/life balance initiatives: results from a national survey of stressful events. Journal of Employment Counseling , 38(March), 38-44. <http://dx.doi.org/10.1002/j.2161-1920.2001.tb00491.x>

Hyman, J., \& Summers, J. (2004). Lacking balance? Work-life employment practices in the modern economy. Personnel Review , 33(4), 418-429. < http://dx.doi.org/10.1108/00483480410539498>

Indexmundi. (2010). Retrieved March 16, 2012, from Indexmundi: http://www.indexmundi.com/bangladesh/unemployment_rate.html

Karatepe, O. K., \& Tekinkus, M. (2006). The effects of work-family conflict, emotional exhaustion, and intrinsic motivation on job outcomes of front-line employees. International Journal of Bank Marketing , 24(3), 173-193. <http://dx.doi.org/10.1108/02652320610659021>

Siegel, P. A., Brockner, J., Fishman, A. Y., Post, C., \& Garden, C. (2005). The moderating influence of procedural fairness on the relationship between work-life conflict and organizational commitment. Journal of Applied Psychology, 90(1), 13-24. <http://dx.doi.org/10.1037/0021-9010.90.1.13>

\section{Appendices}

\section{Table A1}

BIC Table (Auto-Clustering)

\begin{tabular}{lcccc}
\hline $\begin{array}{c}\text { Number of } \\
\text { Clusters }\end{array}$ & $\begin{array}{c}\text { Schwarz's Bayesian } \\
\text { Criterion (BIC) }\end{array}$ & BIC Change $^{\mathrm{a}}$ & Ratio of BIC Changes $^{\mathrm{b}}$ & Ratio of Distance Measures $^{\mathrm{c}}$ \\
\hline 1 & 10494.280 & & & 1.859 \\
2 & 9814.073 & -680.206 & 1.000 & 1.915 \\
3 & 9635.022 & -179.051 & .263 & 1.086 \\
4 & 9734.568 & 99.545 & -.146 & 1.084 \\
5 & 9858.341 & 123.774 & -.182 & 1.174 \\
6 & 10003.730 & 145.388 & -.214 & 1.334 \\
7 & 10187.512 & 183.782 & -.270 & 1.087 \\
8 & 10426.459 & 238.947 & -.351 & 1.016 \\
9 & 10678.625 & 252.166 & -.371 & 1.052 \\
10 & 10933.113 & 254.487 & -.374 & 1.012 \\
11 & 11195.007 & 261.894 & -.385 & 1.116 \\
12 & 11458.569 & 263.562 & -.387 & 1.105 \\
13 & 11736.769 & 278.201 & -.409 & 1.008 \\
14 & 12026.895 & 290.126 & -.427 & 1.002 \\
15 & 12317.947 & 291.052 & -.428 & \\
\hline
\end{tabular}

Note. a. The changes are from the previous number of clusters in the table.

b. The ratios of changes are relative to the change for the two cluster solution.

c. The ratios of distance measures are based on the current number of clusters against the previous number of clusters. 


\section{Important Variables for Clusters}

TwoStep Cluster Number $=1$

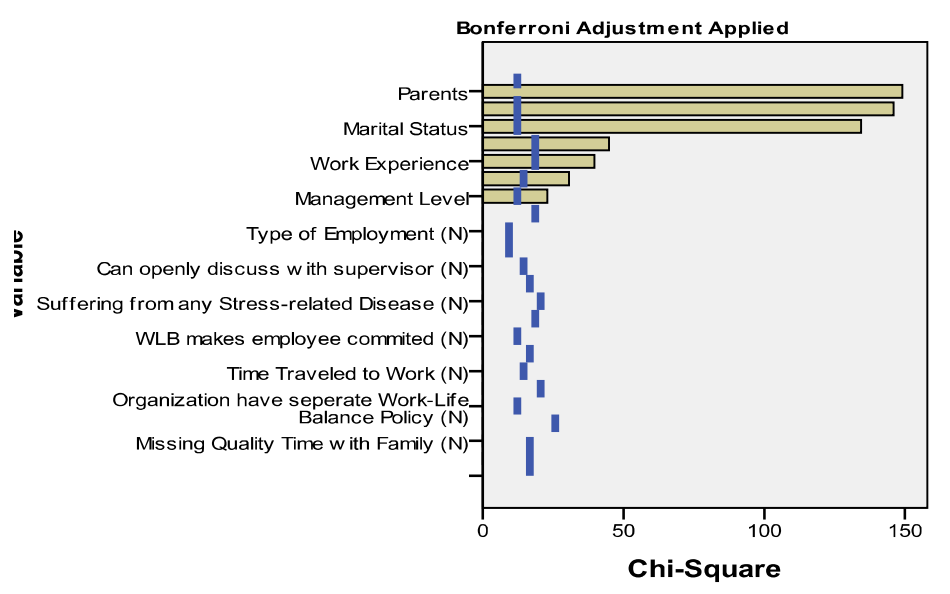

Critical Value

Test Statistic

(N) Non-significant

TwoStep Cluster Number $=2$

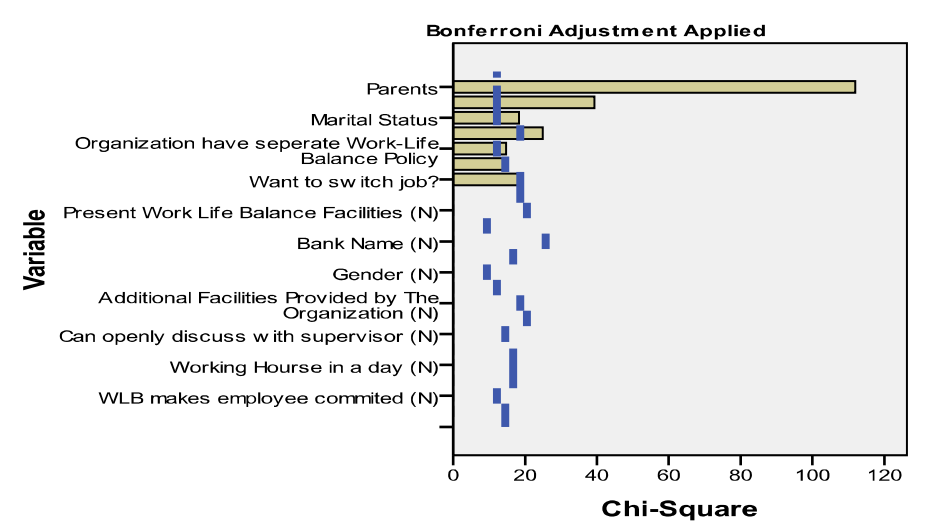

Critical Value
Test Statistic

(N) Non-significant

TwoStep Cluster Number $=3$

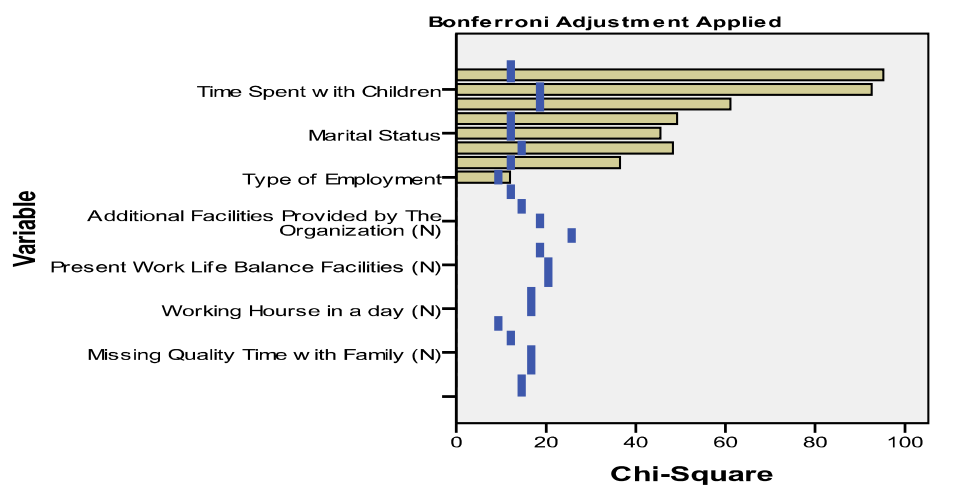

$\square$ Critical Value

(N) Non-significant

Figure A1. Cluster wise important variables 